\title{
Cidade e turismo: o valor de consumo da (contra)paisagem cultural carioca
}

Eder Malta ${ }^{1}$

Resumo

A patrimonialização da paisagem cultural da cidade do Rio de Janeiro foi uma estratégica política de valorização paisagística, revitalização das áreas históricas e de recomposição da imagem turística. A partir de revisão de literatura e observações diretas, entendemos que o uso da noção de paisagem cultural, conceito mais abrangente que o de patrimônio histórico, tornou-se um importante recurso para reposicionar o Rio no processo global de concorrência intercidades, ao tempo que conformou um processo de concorrência intracidade em torno da paisagem turística. Diversas ações públicoprivadas foram implantadas para agregar "valor de consumo" aos bens culturais, atrair investimentos e capitais que, por um lado, estimularam o enobrecimento de espaços públicos, inclusive de favelas. Por outro, as favelas tornaram-se uma "contra-paisagem", ora inserida no mapa turístico, ora ameaçadas de remoção.

Palavras-Chave: Consumo. Paisagem Cultural. Contra-Paisagem. Patrimonialização. Turismo.

\section{CITIES AND TOURISM: CONSUMPTION VALUE OF CARIOCA CULTURAL (COUNTER)LANDSCAPE}

\section{Abstract}

The patrimonialisation of the cultural landscape of Rio de Janeiro was a strategic policy of landscape appreciation and protection, revitalization of historical areas and recomposition of touristic image. Through specialized literature revision and observations made in the city, we understood that the use of the cultural landscape notion, a concept which is more broadening than historical heritage, became an important resource in order to reposition Rio in the global intercity competition process, while it conformed an intracity competition process regarding the Rio's touristic landscape. Many public-private actions were implemented to add "consumption value" to cultural goods and attract investments and capitals that, on the one hand, stimulated the gentrification of public spaces, including of some "favelas". On the other, the "favelas" became a "counter-landscape", sometimes inserted in the touristic map, other times threatened with removal from the public power.

Keywords: Consumption. Cultural Landscape. Counter-landscape. Patrimonialisation. Tourism.

1 Pós-doutorado (PNPD/CAPES) pelo PPGS da Universidade Federal de Pelotas (UFPel). Doutor em Sociologia pelo PPGS da Universidade Federal de Sergipe. 


\section{Introdução}

As paisagens cariocas constituem um dos principais atrativos turísticos internacionais do Brasil desde o processo de modernização da cidade do Rio de Janeiro no início do Século XX. Desde então, apesar de figurar como cartão-postal nacional com o epíteto "Cidade Maravilhosa" - uma cidade identificada pelo cosmopolitismo urbano-cultural -, somente após sua patrimonialização pela Organização das Nações Unidas para Educação, a Ciência e a Cultura(UNESCO), em 2012, tem-seinvestidoem políticas de proteção paisagística e do "ambiente cultural" carioca para manter sua integridade e autenticidade visual (UNESCO, 2012). As principais ações objetivam o desenvolvimento econômico sustentável e a recomposição turística e da imagem do Rio de Janeiro para além de um balneário Atlântico.

$\mathrm{Na}$ tentativa de promover uma autêntica imagem urbana com o selo do patrimônio mundial, o poder público, em parceria com os investidores privados, realizou intervenções urbanas com vistas à valorização patrimonial em regiões estratégicas, desde os espaços públicos e as paisagens urbanas da Zona Sul - símbolos da modernidade carioca - às novas paisagens turísticas das Zonas Central e Portuária, que se tornaram espaços de sociabilidade e consumo cultural. Após a patrimonialização intensificaram-se os casos de gentrificação nessas localidades que se estendem, inclusive, para alguns morros favelizados, com vista para a Baía de Guanabara.

Entendemos que o objetivo das políticas de patrimonialização é a valorização dos bens culturais materiais e imateriais, dos lugares e das paisagens associadas aos espaços capazes de agregar valor de consumo (HOLBROOK et al., 1999; MALTA, 2017a, 2017b) - cultural, visual e simbólico - para a atração de investimentos dos setores privados. Neste sentido, Leite (2015) observa que a crescente participação do setor privado na gestão deáreas e bens patrimoniais tem almejado lucrativas oportunidades de negócios e impulsionado uma complexa alteração conceitual do patrimônio - e de paisagem cultural adaptando-o à nova lógica do mercado, ou seja, tratando esse patrimônio não mais como "bem simbólico", mas sim como uma "mercadoria cultural". Na prática, conforme argumenta Leite (2015, p. 176), esse "processo implica no reconhecimento de formas de interação baseadas no consumo e pressupõe [...] selecionar bens que potencialmente possam corresponder às expectativas de retorno financeiro dos altos investimentos privados" 2 .

A recomposição da imagem do Rio de Janeiro foi intermediada por práticas de turismo e consumo cultural e compreende a associação dos elementos simbólicos e representacionais como recursos potenciais de sustentação das economias locais que servem para as cidades se reposicionarem no processo de concorrência intercidades (FORTUNA, 1997). A metodologia aplicada neste trabalho baseouse no levantamento da arte acerca do atual debate sobre o patrimônio cultural do Rio e nas observações diretas que realizamos na cidade desde a nominação do sítio em 2012. Dentre os resultados que observamos foi que a captura da noção de paisagem cultural pela lógica de mercado tem intensificado a "concorrência intracidade" (MALTA, 2017b), processo que altera o sentido habitual da paisagem cotidiana em torno da construção da paisagem turística. Tal processo refere-se à concorrência entre os investidores translocais para a atração de consumidores às práticas de consumo e turismo, desde os morros favelizados - a que chamamos "contrapaisagens" cariocas que, quando não são removidas ou excluídas do mapa turístico, ${ }^{3}$ tornam-se disputados lugares de hospedagem, aventuras, emoções e exotismos turísticos (FORTUNA, 2012) — até os revitalizados espaços

2 Tradução livre de "process implies the recognition of forms of interaction based on the consumption and presupposes [...], electing assets with the potential to meet the expectations for a financial return on the substantial investments made by the private sector".

3 A recorrência de notícias como "Folhetos distribuídos a turistas que chegam ao Rio não mostram favelas", em que o Jornal O Globo, em 11/9/2017, revela ações da RioTur em ocultar as favelas do mapa turístico do Rio. Apesar de ser uma decisão política, a alegação é que foi uma decisão baseada em critérios técnicos. 
do Centro e Zona Portuária.

Este artigo discute criticamente sobre a patrimonialização da Paisagem Cultural carioca com o objetivo principal de analisar o processo de valorização paisagística e de recomposição turística da cidade. Atrelado à noção de paisagem cultural como instrumento técnico e conceitual inovador de preservação patrimonial e ambiental, esse processo procura reeditar o cronograma das políticas de intervenção que emergiram na cidade desde os anos de 1980. Em suma, visase recompor a imagem turística carioca, a partir de seus patrimônios, para a atração de pessoas, investimentos sustentáveis e capital ${ }^{4}$.

Isso nos leva a questionar: em que medida esses processos deslocam o "valor" conferido à paisagem cultural de um bem sociocultural para um bem consumível? As oportunidades da turistificação podem oferecer, aos gestores públicos e investidores privados, estratégias políticas e de expansão dos mercados de bens culturais, mas de que modo promovem a sustentabilidade da cidade? A resposta do poder público decorreu de um intenso marketing urbano em torno da paisagem e do patrimônio que designou ao Rio diversas identidades, como cidade criativa, sustentável, segura, de inovadora mobilidade urbana e tecnológica, vinculadas à criação de paisagens turísticas (VAN DER DUIM, 2007) e às práticas de consumir a cidade.

\section{Da Zona Sul à Zona Portuária: estratégias para a valorização paisagística e patrimonial}

No ano de 1992, a Convenção da UNESCO para o patrimônio mundial adotou o conceito de Paisagem Cultural como tipologia de reconhecimento e preservação dos bens culturais. Como estratégia, promove-se a integração entre a vida cotidiana, os bens culturais e o meio ambiente, pondo fim à dicotomia existente entre patrimônio cultural e natural, e entre patrimônio material e imaterial, embora manteve-se a categoria associada aos critérios de "excepcionalidade" e "autenticidade" (RIBEIRO, 2007; MALTA, 2017a, 2017b).

Para Costa e Serres (2016), as paisagens culturais não só puseram fim à antinomia materialidade e imaterialidade e entre patrimônio cultural e natural, como também anteciparam a institucionalização da categoria de patrimônio imaterial que viria a ser reconhecida somente em 2003. O conceito envolve diferentes sentidos consolidados no tempo acerca da noção de patrimônio, de preocupação com o meio ambiente e com a preservação da vida futura. Noções de natureza, memória, identidades culturais e territoriais foram vinculadas às políticas de patrimonialização de modo que a chancela da paisagem cultural se tornasse uma importante estratégia de integração entre a vida cotidiana, os bens culturais e o meio ambiente.

$\mathrm{Na}$ Europa, a regulamentação da proteção paisagística foi aprovada em 1995 pelo Conselho Europeu e, posteriormente, pela Convenção Europeia da Paisagem, no ano 2000. Esta Convenção estabelece que as políticas de preservação abrangessem todas as paisagens que fazem parte da vida social e cultural dos territórios, e incidisse sobre a qualidade paisagística das áreas naturais, rurais, urbanas e peri-urbanas, não sendo necessariamente atribuída às paisagens excepcionais ou que estejam em estado de degradação ${ }^{5}$.

No Brasil, desde a década de 1980, as práticas preservacionistas do IPHAN têm priorizado a patrimonialização das cidades antigas e centros históricos coloniais. O foco girou principalmente em torno das características estéticas dos monumentos, do passado político e religioso

4 Esse artigo foi escrito pouco antes do incêndio do Museu Nacional do Rio de Janeiro, em 2 de setembro de 2018. O Museu Nacional, localizado na Quinta da Boa Vista, é uma das instituições científicas e antropológicas mais importantes da América Latina. O desastre ocorreu no ano em que se comemoram os 200 anos da fundação do Museu Nacional e os 50 anos da criação do Programa de Pós-Graduação em Antropologia Social (PPGAS/MN/UFRJ). Desde 2015, a UNESCO já alertava para a situação do museu. Mais detalhes em $<$ http://www.unesco.org/new/pt/brasilia/about-thisoffice/single-view/news/unesco_in_brazil_regrets_fire_on_the_national_museum/>. Como observação crítica, tal situação demonstra que a política de patrimonialização possui limitações nas ações de conservação dos monumentos nacionais fora da rota do consumo cultural. Uso habitual e sustentável dos bens culturais, como veremos, permanece secundário aos interesses dos gestores públicos e investimentos privados.

5 Para detalhes ver o documento Convenção Europeia Da Paisagem. Convenção de Florença, Florença, 2000. 
luso-brasileiro, a exemplo das cidades mineiras do ciclo do ouro. Somente após três décadas, em 2009, o IPHAN regulamentou a chancela da Paisagem Cultural na Portaria no 127/2009 como novo instrumento de preservação do patrimônio brasileiro. A partir de então propôs revisão metodológica, conceitual, inovação técnica e instrumental das políticas de patrimonialização, embora já houvessem bens naturais considerados paisagens culturais brasileiras ${ }^{6}$.

Com base nas concepções da UNESCO e da Convenção Europeia da Paisagem, a chancela da paisagem cultural brasileira decorre da associação entre os bens culturais e naturais reivindicados desde seu caráter excepcional a sua proximidade com a vida cotidiana das populações. Convém observar que desse período em diante ocorreram importantes mudanças no escopo da política de patrimonialização no país com o fim de um dos mais abrangentes programas de preservação e revitalização patrimonial, o Programa Monumenta (2001-2010), e com o início das atividades do Programa de Aceleração do Crescimento das Cidades Históricas (PAC$\mathrm{CH})$, em 2010.

Três anos depois, em 2012, a cidade do Rio de Janeiro recebe a chancela mundial de Paisagem Cultural (embora não tenha sido chancelada em âmbito nacional) pelo Comitê do Patrimônio Mundial da UNESCO que aprovou o dossiê de candidatura "Rio de Janeiro: paisagens cariocas entre a montanha e o mar", resultado de um estudo pluridisciplinar cuja elaboração foi coordenada pelo IPHAN/DF e por uma extensa equipe técnica e acadêmica formada por consultores arquitetos, urbanistas e geógrafos ${ }^{7}$. Neste documento defende-se que o "valor universal excepcional" da Paisagem Cultural carioca é resultado do processo histórico de intervenções urbanas "em forte presença de elementos da natureza no meio urbano [...] onde o equilíbrio entre elementos naturais e construídos confere qualidade ambiental e social" (IPHAN, 2012, p. 14) à vida urbana carioca. A paisagem cultural-urbana é representada como um estágio civilizatório diante dos próprios desafios e das contradições presentes no processo de apropriação da natureza e de desenvolvimento da cidade como "singularidade cultural da sociedade brasileira" (IPHAN, 2012, p. 07).

Com base em tais concepções, o IPHAN (2012) defende que a excepcionalidade do sítio tem relação direta com a vida cotidiana carioca e com seus espaços públicos associados a um singular paisagismo de inspiração artística aplicado pelos princípios do urbanismo modernista construído entre as montanhas existentes e a entrada da Baía de Guanabara. Para o IPHAN, a excepcionalidade das paisagens urbanas-culturais e naturais como os morros, as praias e as autênticas formas de expressão culturais inscrevem o modo de vida carioca, as sociabilidades "ao ar livre", a arquitetura e o urbanismo cosmopolita no entremeio de uma "paisagem única" de uma metrópole tropical, isto é, de concretos construídos ligados à natureza marcante.

O sítio paisagístico tornou-se a primeira área urbana chancelada como Paisagem Cultural pela Convenção do Patrimônio da UNESCO ${ }^{8}$. As ações previstas pela Convenção da UNESCO (2012) deveriam girar em torno do então recém-

6 No Brasil, as localidades consideradas Paisagem Cultural são bens naturais: bens naturais, o Parque Nacional do Iguaçu (1986), as Reservas de Mata Atlântica do Sudeste e as Reservas de Mata Atlântica da Costa do Descobrimento (1999), o Parque Nacional do Pantanal Mato-grossense e o Parque Nacional do Jaú (2000), os Parques nacionais de Chapada dos Veadeiros e das Emas (2001).

7 A elaboração da proposta foi coordenada pelo IPHAN por meio do Decreto do No 127, de 30 de abril de 2009, e contou com a participação do Governo do Estado do Rio de Janeiro, por meio do Instituto Estadual de Patrimônio Cultural (INEPAC), da Prefeitura da Cidade do Rio de Janeiro, do Instituto Chico Mendes de Conservação da Biodiversidade (ICMBio) e da Fundação Roberto Marinho.

8 Após o título do Rio de Janeiro em 2012, no ano de 2016, a UNESCO declarou o Conjunto Moderno da Pampulha, em Belo Horizonte (MG), Paisagem Cultural do Patrimônio Moderno. Tal consideração importa-nos à argumentação, como veremos, sobre a patrimonialização dos bens modernistas brasileiros. Além disso o Sítio Arqueológico do Valongo, no Rio de Janeiro (RJ), foi declarado Patrimônio Cultural e parte da Rota dos Escravos pela UNESCO, em 2017, e representa o primeiro sítio de matriz africana reconhecido no Brasil. 
criado Plano Diretor de Desenvolvimento Urbano Sustentável (PDDU/2011), instituído pela lei complementar n. 111/2011, que revisa o Plano Diretor de 1992 e dispõe sobre a política urbana e ambiental. Destacamos aqui os três primeiros princípios da política urbana formulada no PDDU com foco I) na noção de desenvolvimento sustentável para promover o desenvolvimento econômico, a preservação ambiental e a equidade social; II) nas noções de função social da cidade e da propriedade urbana; e III) na política de valorização e sustentabilidade ambiental, paisagística e patrimonial no processo de desenvolvimento do planejamento urbano da cidade.

Convém notar que a noção de sustentabilidade não esteve claramente em questão nos planos diretores e de intervenção anteriores ao PDDU/2011, a exemplo do Plano Diretor de 1992, tampouco esteve aliada à perspectiva de desenvolvimento econômico e valorização paisagística. Tal noção foi concebida na política de planejamento urbano associada à proteção patrimonial, ambiental e da visualidade da paisagem (contra o excesso de interferências visuais e regula a construção de grandes projetos urbanísticos, imobiliários, etc.) e subsidiou os critérios para a nominação. $\mathrm{O}$ abrangente plano de reestruturação urbana e ambiental agrega o componente da sustentabilidade para reverter, por um lado, a ocupação irregular dos morros que reside na favelização e, por outro, a lógica de arrasamento dos morros que ocorrera em planos de intervenção urbana entre os anos de 1920 e $1950^{9}$.

Apesar de ser um conceito inovador, a paisagem cultural não define um perfil específico dos bens por possuir abrangência genérica $\mathrm{e}$ de múltiplas possibilidades. Conforme aponta Ribeiro (2011, p. 259), "além da concepção de tudo englobar, é a leitura do patrimônio através do espaço. Trata-se claramente de uma abordagem espacial e de uma interpretação dos fenômenos a partir de sua localização e de sua relação com outros no espaço". Neste sentido, a escala de abrangência de um sítio paisagístico é delimitada a uma determinada porção espacial ou recorte territorial e remete sempre a um conjunto espacial concebido de conteúdos, representações e significados socioculturais peculiares e construídos em associação à morfologia e às formas naturais de um determinado território.

Essa ampla abordagem constitui seu maior risco, haja vista as pressões dos mercados e grupos de interesses (RIBEIRO, 2011). Possibilita também uma estratégia de identificação e de gestão do patrimônio de modo descentralizado e flexível. Exemplo dessa perspectiva é que, estrategicamente, o dossiê não inclui a região Central e a Zona Portuária nos limites iniciais do sítio. No entanto, principalmente no período dos megaeventos esportivos - Copa do Mundo de 2014 e Olimpíadas de 2016 - esses dois bairros foram alvos das principais políticas de intervenção da Prefeitura da Cidade do Rio de Janeiro (PCRJ) (MALTA, 2017a).

Após a nomeação do sítio, a PCRJ criou o Instituto Rio Patrimônio da Humanidade $(\mathrm{IRPH})^{10}$ como órgão gestor das ações de revitalização urbana e de proteção à visualidade das zonas estratégicas de interesse cultural e paisagístico. No âmbito do IRPH, foi instituído o Programa de Apoio à Conservação do Patrimônio Cultural Edificado (PRÓ-APAC), que possui forte atuação na delimitação de áreas especiais de interesse paisagístico e de proteção do ambiente cultural com fins de apoiar financeiramente os projetos de conservação e restauro de imóveis preservados ou tutelados pelo município (PCRJ, 2012). O PDDU/2011 torna as APACs o principal instrumento básico de gestão e proteção do patrimônio cultural e delimita as "zonas estratégicas de especial interesse" para as políticas urbanas de valorização paisagística e de promoção de políticas culturais.

Através do Pró-APAC, o IRPH passou a elaborar projetos e políticas de intervenção em parcerias com instituições privadas e agências multilaterais nacionais e internacionais. A execução das principais políticas urbanas,

9 Um dos expoentes dessas intervenções foi a demolição do Morro do Castelo entre 1920 e 1922, sob a justificativa em combater as condições precárias de higiene, a degradação e a favelização do Centro. No final da década de 1950, ocorreu o desmonte do Morro de Santo Antônio para a construção do Aterro do Flamengo.

10 Criado pelo decreto n. 35.879 de 5 de julho de 2012, após a nomeação da cidade como Patrimônio da Humanidade. 
ambientais e culturais municipais ocorre em torno da identificação, do tombamento de bens edificados e do registro do patrimônio imaterial inscritos em Áreas de Proteção do Ambiente Cultural (APAC), que se sobrepõem às zonas e subzonas da cidade. São priorizados os espaços - de domínio público ou privado - que sejam caracterizados como um conjunto edificado de relevante interesse cultural para a memória da cidade e para a diversidade da ocupação urbana que atraiam investimentos para a inovação dos usos espaciais e socioculturais sob o argumento de evitar o "engessamento" da área urbana (CARLOS, 2008). Intervenções dessa natureza promoveriam o desenvolvimento sustentável, a proteção da visualidade e da ambiência da paisagem cultural, evitando, assim, a perda potencial de sua "originalidade".

No período dos megaeventos, a prefeitura concentrou os investimentos poliesportivos na Barra da Tijuca, em Jacarepaguá e algumas regiões da zona Oeste. $\mathrm{Na}$ política urbana de patrimonialização, o IRPH tem se concentrado principalmente no eixo de intervenção da região Central e Zona Portuária. Esse movimento decorre de uma estratégia com dupla perspectiva. Em primeiro lugar, visou-se atrair pessoas, serviços de consumo, turismo e capitais, desde investimentos internacionais até atração de novos moradores e comércio local para promover a reestruturação econômica e o turismo nesses bairros, no âmbito da política de patrimonialização.

Entre os objetivos e as ações previstas em torno do desenvolvimento sustentável, buscou-se regulamentar os usos do mobiliário urbano, recuperar e revitalizar os conjuntos arquitetônicos, ruas e praças, para promover o patrimônio cultural e atrair investidores para a criação de novos equipamentos urbanos sustentáveis. Conforme Guimarães (2016), essas ações visaram estabelecer os planos de “integração/ordem urbana” e de revitalização urbana da APAC Sagas nos bairros portuários da Saúde, Gamboa e Santo Cristo e "foram utilizadas para segmentar as medidas de 'revitalização', operando, assim, como um relato que não só identificou valores culturais como também produziu novas realidades" (GUIMARÃES, 2016, p. 160).
O segundo aspecto decorre do processo de patrimonialização da Zona Sul, espaço que concentra o imaginário de vida ao ar livre, da cultura praiana e do ideário de construções modernistas e cosmopolitas do Rio de Janeiro e mesmo do Brasil. Essa zona foi erigida sob inspiração haussmaniana e influência do paisagismo de Adolphe Alphand, devido à importação do modelo dos jardins, canteiros floridos, gramados e a arborização dos espaços públicos. Alguns desses espaços foram desenhados pelo artista plástico e arquitetopaisagista Roberto Burle Marx, tais como o mosaico em ondas que formam o calçadão da orla de Copacabana e o aterro do Flamengo. Desde a expansão da Zona Sul, vincularam-se a vida urbana e as práticas socioculturais cariocas aos espaços de consumo cultural e à paisagem turística da cidade. Com os megaeventos, proliferou-se a especulação imobiliária em torno dos bairros inscritos no sítio paisagístico que pressionava o perfil habitacional de usos e estilos de vida dos antigos moradores e das camadas populares. Como aponta Guimarães:

A patrimonialização da Zona Sul teve assim a função de conduzir de forma indireta $o$ desenvolvimento urbano, com a vantagem para a Prefeitura de contar com a adesão de algumas associações de moradores, que perceberam na medida a possibilidade de manter as características arquitetônicas e ambientais dos bairros e evitar a chegada de uma numerosa vizinhança. [...] Do ponto de vista urbanístico, no entanto, a medida cumpriu sua função estratégica: a construção civil de fato encontrou maior dificuldade de atuar na Zona Sul e transferiu seus investimentos para outras regiões da cidade, inclusive para a região portuária. (Ibid., p. 162-163)

A consolidação das APACs desloca o fluxo de investimentos imobiliários para a Zona Portuária, que desde o início da realização do projeto Porto Maravilha, em 2009, passa pela intensificação das iniciativas do mercado através da maior parceria público-privada na história brasileira para a revitalização e a renovação urbana (PIO, 2013; BROUDEHOUX e MONTEIRO, 2017). Isto possibilitou a proteção da ambiência residencial e a restrição de novas construções de impacto 
socioambiental e arquitetônico na Zona Sul que colocassem em risco a autenticidade paisagística dos espaços públicos ou descaracterizassem a qualidade de vida das comunidades residenciais dessa zona, em bairros como Lido, Peixoto e Leblon, que possuem ambiência cotidiana tradicional.

Para o Centro Histórico, foi instituído o programa "Centro para Todos", no ano de 2015, que tem como princípios de intervenção o ordenamento, a segurança, a higienização e a iluminação dos espaços públicos características recorrentes nas políticas de revitalização das áreas históricas orientadas pelos processos de gentrificação. Esse programa dividiu suas ações em nove áreas: Praça Tiradentes, Centro Financeiro, Praça XV, Cinelândia, Lapa, Cruz Vermelha, Saara, Castelo e Campo de Santana. Tem como características promover a reocupação residencial, mapear os "vazios urbanos", promover índices de caminhabilidade, transportes sustentáveis, como bicicletas e Veículo Leve sobre Trilhos (VLT), atrair setores da indústria criativa, etc. Tais ações visam reocupar e revitalizar o Centro como lugar de moradia, lazer e consumo. ${ }^{11}$

Torna-se evidente a intenção do instituto em promover uma forte ação de gentrificação com base nas noções de ordem, limpeza e segurança para garantir à cidade a sensação de vida ao ar livre e sustentabilidade nas áreas históricas. Esse cenário possibilitou não só a expansão das políticas urbanas de patrimonialização para a Zona Portuária e região Central, mas deu margem à política de incentivo à moradia e ao investimento, nessas áreas, como lugar de consumo, boemia, vida noturna e turismo cultural. Focaremos, a seguir, na abrangência do processo de recomposição turística que se estabeleceu em grande parte da área delimitada como sítio Paisagem Cultural.

\section{Paisagens e contra-paisagens: turismo, enobrecimento e imagem urbana}

As políticas de patrimonialização têm como um de seus objetivos centrais a valorização dos bens culturais materiais e imateriais, dos lugares e das paisagens. Segundo Rubino (2008), compreende-se que este processo se impõe não necessariamente pela "perda do bem", mas invertendo-a para a "agregação de valor", com enfoque à cenografia de presumida autenticidade e à renovação dos usos para eventos, lazer, consumo cultural, turismo e especulação imobiliária. Contrariamente à tese dos movimentos modernos da arquitetura de que os bens antigos eram um fator impeditivo para o progresso urbano, a década de 1980 viu o lema da preservação patrimonial tornar-se uma importante política urbana para captação de investimentos financeiros sob o discurso de agregar valor aos bens culturais na promoção da cidadania, mas centralmente para alavancar o desenvolvimento econômico e social das cidades.

Para Meneses (2002), quando um bem coletivo é valorizado como "bem cultural" (após sua intervenção com qualidades técnicas e políticas voltadas à representação de uma identidade), tenciona-se levar à dissociação entre o uso cultural dos turistas e o uso qualificadamente existencial/habitual que as pessoas fazem dos lugares em que constroem suas práticas habituais e memórias, tais como as igrejas e as praças, os saberes e os fazeres, isto é, entre os bens dotados de valores qualitativamente pragmáticos e afetivos. Meneses (2012, p. 29) refere-se, portanto, à tese "universalizante" das práticas de preservação que é antes seletiva: "De passagem observo que a política de patrimônio imaterial que o IPHAN vem desenvolvendo procura reconhecer que o campo cultural diz respeito à totalidade da vida social, quando diferencialmente qualificada (pelos sentidos, valores)”. A constante vinculação entre patrimônio e desenvolvimento socioeconômico põe em risco a pretensa criação de valores multiculturais às representações dos bens e incorre na possibilidade da perda de seu "potencial de interlocução", a começar pelos

11 O índice de caminhabilidade é realizado pelo Instituto de Políticas de Transporte e Desenvolvimento (ITDP-Brasil) em parceria com o IRPH. Mais detalhes em: <http://itdpbrasil.org.br/indice-de-caminhabilidade/>. O mapeamento dos vazios urbanos é uma realização de censo com a identificação e a caracterização de imóveis vazios e subutilizados. Mais detalhes em: <http://www.rio.rj.gov.br/web/irph/exibeconteudo?id=6588530>. 
interlocutores locais, de modo que se "esvaziem legítimos sentidos e práticas originais locais, que não correspondem mais a uma nova ordem de interesses" (Idem, ibidem).

Diante das interfaces que as políticas urbanas de patrimonialização estão estruturadas pelo mercado e para ele, consideramos que as intervenções ocorrem mediante a atribuição do valor de consumo dos bens culturais. Sobre a criação de valores na sociedade de consumo, Holbrook et al. (1999) argumenta que é fundamental entender a natureza dos tipos de valores que os consumidores obtêm através da experiência do consumo seja ele individual ou coletivo, material ou imaterial etc. $\mathrm{O}$ autor apresenta um quadro tipológico acerca da atribuição de valores pessoais do consumidor $\mathrm{e}$ como estes valorizam os bens culturais que inclui características desde a eficiência, a excelência, o status, a estima, o jogo, a estética, a ética e até a espiritualidade.

A compreensão dessas categorias de valores de consumo leva em conta a interação entre consumidor e o produto, as avaliações, as comparações, os julgamentos de preferência e a experiência com os bens de consumo que permeiam entre o valor extrínseco e o valor intrínseco associado às funcionalidades $\mathrm{e}$ finalidades dos bens e serviços; a auto-orientação (fruição do consumidor para seu próprio proveito) e a alter-orientação (reação de terceiros com relação ao consumo do "outro"). Por fim, Holbrook ainda concebe as noções de valor de consumo ativo e valor de consumo reativo, que respectivamente correspondem à manipulação física ou simbólica dos bens materiais ou imateriais e ao modo como tais bens provocam a apreciação e uma resposta do consumidor ${ }^{12}$.

Partindo das premissas simmelianas acerca da predominância da cultura objetiva sobre a subjetividade, da mobilidade (ou relatividade) dos valores e da redução das singularidades dos objetos e pessoas a um valor monetário quantitativo, Featherstone $(2007,2011)$ concebe que os valores, ou melhor, a invenção de valores pode ser ligada à cultura de consumo que, por um lado, é tanto antipática quanto pragmática em relação aos valores, pois presume o cálculo racional e os meios sobre os fins, que podemos exemplificar através da distinção acima feita por Meneses (2012) acerca do uso qualificadamente existencial/habitual/afetivo e do uso cultural ou pragmaticamente turístico. Por outro lado, a ênfase contemporânea no "consumo de valores" enfoca as identidades e grupos sem status fixos, em que os estilos de vida baseiam-se na pluralidade das escolhas para a autorrealização e o prazer de viver uma vida episódica conformada no lazer, no vestuário, na excitação, nas aventuras e na constante auto-invenção exultada por meio de bens de consumo. Com base nas noções mencionadas acima, compreendo que a criação de valores de consumo decorre da inter-relação de valores de troca e de uso não somente na aquisição imediata dos bens, mas pela dimensão cultural da economia e pela economia dos bens culturais. Essa dupla condição abrange os processos de mudança nas dimensões materiais e imateriais da vida cotidiana, cada vez mais intermediadas pela cultura de consumo.

Partimosdessasconcepçõespara discutirsobre a representação consumível da paisagem cultural carioca que reforça, sobretudo, a visualidade material e simbólica das paisagens de poder da cidade, traduzidas na interação entre o homem e a natureza. Segundo Zukin (2000) a paisagem é, "em grande parte, uma construção material, mas também é uma representação simbólica das relações sociais e espaciais [...] é uma poderosa expressão das restrições estruturais de uma cidade" (p. 106). É na paisagem que podemos observar o que foi construído, escondido e o que resiste às mudanças estruturais da cidade. A paisagem ordena socioespacialmente a estrutura urbana, conforma relações sociais de poder político, de poder econômico e de diferenças culturais, portanto, sua representação simbólica e material constitui uma "paisagem de poder" (ibid.).

Com base na noção de paisagem postulada por Zukin (2000), podemos inferir que a favela é a contra-paisagem carioca, isto é, um espaço

12 Para uma discussão detalhada acerca dessa tipologia e seus desdobramentos nos estudos de marketing do esporte, fast-food etc. ver Holbrook et al. (1999), Sauerbronn; Ayrosa (2004) e Schröder; McEachern (2005). 
de inversão do planejamento e da representação simbólica de poder que promove uma tensão estrutural na espacialidade urbana sobre as restrições estruturais e as dimensões normativas do espaço urbano estratégico (MALTA, 2017a, 2017b). As favelas constituem a representação antissimbólica carioca (BARBOSA, 2012) e, como uma contra-paisagem, são comumente caracterizadas pela representação social de degradação dos morros paisagísticos.

A paisagem cultural enaltece o mosaico urbano no entremeio de paisagens naturais que se constituiu no decorrer de intervenções urbanas sucessivas, projetadas para a construção de uma cidade moderna, competindo com suas próprias dificuldades técnicas para construir um aglomerado urbano entre o mar e os morros. Sua singularidade é, conforme retrata o IPHAN (2012), representada pelo desenho "intencional" da paisagem, isto é, projetada para ser cartãopostal brasileiro, de modo que suas imagens sejam "refletidas para o mundo" como uma marca espaço-temporal que inscreveu o poder político e identitário da arquitetura, do urbanismo e do paisagismo da modernidade carioca.

Essas características são reivindicadas como "marca Rio", fruto da internacionalização do imaginário carioca e de seus espaços culturais - Maracanã, Copacabana, Ipanema, Corcovado, Pão de Açúcar, Samba, Bossa Nova. Mas essa marca passa por um processo de recomposição de sua própria narrativa e representação, de tal modo que esse processo gera um duplo movimento de transformação identitária ${ }^{13}$.

Em primeiro lugar, a Floresta da Tijuca, o Jardim Botânico, o Morro do Corcovado e o Pão de Açúcar, consolidaram-se como cartõespostais da paisagem da Cidade Maravilhosa. Tais bens e espaços estão entre os principais ícones que compõem as imagens cenográficas da vida urbana carioca. Mas, para que continuem a representar o branding imagético e publicitário carioca (JAGUARIBE, 2011) e, em certa medida, do Brasil, foram também patrimonializados, de modo que a narrativa e os monumentos da modernidade carioca do século XX tiveram antecipados seu valor tradicional. A transformação em bens tradicionais desses bens culturais e naturais associados à modernidade do Rio atua em seus significados simbólicos, socioculturais, políticos e econômicos.

Em segundo lugar, nossa pesquisa sugere que as intervenções na orla de Copacabana e na Zona Portuária, por exemplo, delineiam uma transformação da imagem e da arquitetura da cidade modernista ${ }^{14}$ para imagem e arquitetura pós-modernista, voltadas às práticas de consumo, tecnologia, entretenimento e a um novo senso de experiência turística. Ao tempo que o argumento central é a conservação de áreas urbanas e naturais para possibilitar a sustentabilidade ambiental e cultural dos bairros, o investimento em paisagens turísticas torna-se uma iniciativa comum na linguagem e discursos oficiais, na própria construção da paisagem sustentável.

As paisagens turísticas, segundo van der Duim (2007), constituem-se de uma rede de atores que inclui pessoas, bens culturais, meios de comunicação, empreendimentos culturais e mídia digitais, etc. Essa noção de paisagem perpassa os usos e as práticas de consumo de serviços e bens oferecidos nos espaços destinados à visitação. Os usuários e os consumidores são atores de uma rede integrada no espaço e no tempo. Portam dispositivos conectados para a mobilidade urbana, para a criação de imagens, para fotografias e mensagens produzidas em tempo real ou destaques em guias de viagem, brochuras e mapas. Por fim, a paisagem turística compreende os espaços relacionais, constitui os "lugares em rede", em que atores e discursos translocais se envolvem e agem sobre o espaço público.

Em função da patrimonialização da Zona Sul - recomendação indicada pela UNESCO desde 2003 - a orla de Copacabana foi considerada

13 As identidades urbanas, signos cariocas "Cidade Maravilhosa”, "Rio Babilônia” e "Rio 40 Graus”, por exemplo, associadas à economia simbólica da paisagem, estruturam seus usos em torno da produção, circulação e consumo de bens culturais (FARIAS, 2017).

14 Refiro-me ao imaginário do Brasil Modernista do início do século XX, quando foi projetado o cenário paisagístico da já tradicional imagem "Cidade Maravilhosa” e suas paisagens e espaços públicos como a orla de Copacabana e o Parque do Flamengo. 
um bem cultural paisagístico devido ao mosaico de pedra portuguesa em forma de ondas de seu calçadão. A paisagem urbana da orla é conformada pelos diversos edifícios e pela rede hoteleira na avenida Atlântica, de diversificada arquitetura. $\mathrm{O}$ projeto de maior mudança visual que sugere as novas tendências da arquitetura e urbanismo do Rio de Janeiro decorre da construção do Museu da Imagem e do Som (MIS), projeto baseado na forma de mosaico do calçadão da orla.

Esse Museu promete oferecer, ao visitante, cinema, interatividade e tecnologia com usos ao ar livre, voltados para o consumo visual da orla. Já o Museu do Amanhã, no Píer Mauá, construído com tecnologias sustentáveis para a captação de água e energia solar, tem representado o novo cartão-postal carioca em um tripé pósmodernista das cidades criativas, sustentáveis e patrimoniais. Pois, além da arquitetura arrojada e diferenciada, propõe novos paradigmas de usos sociais dos espaços culturais através de mídias e tecnologias criativas.

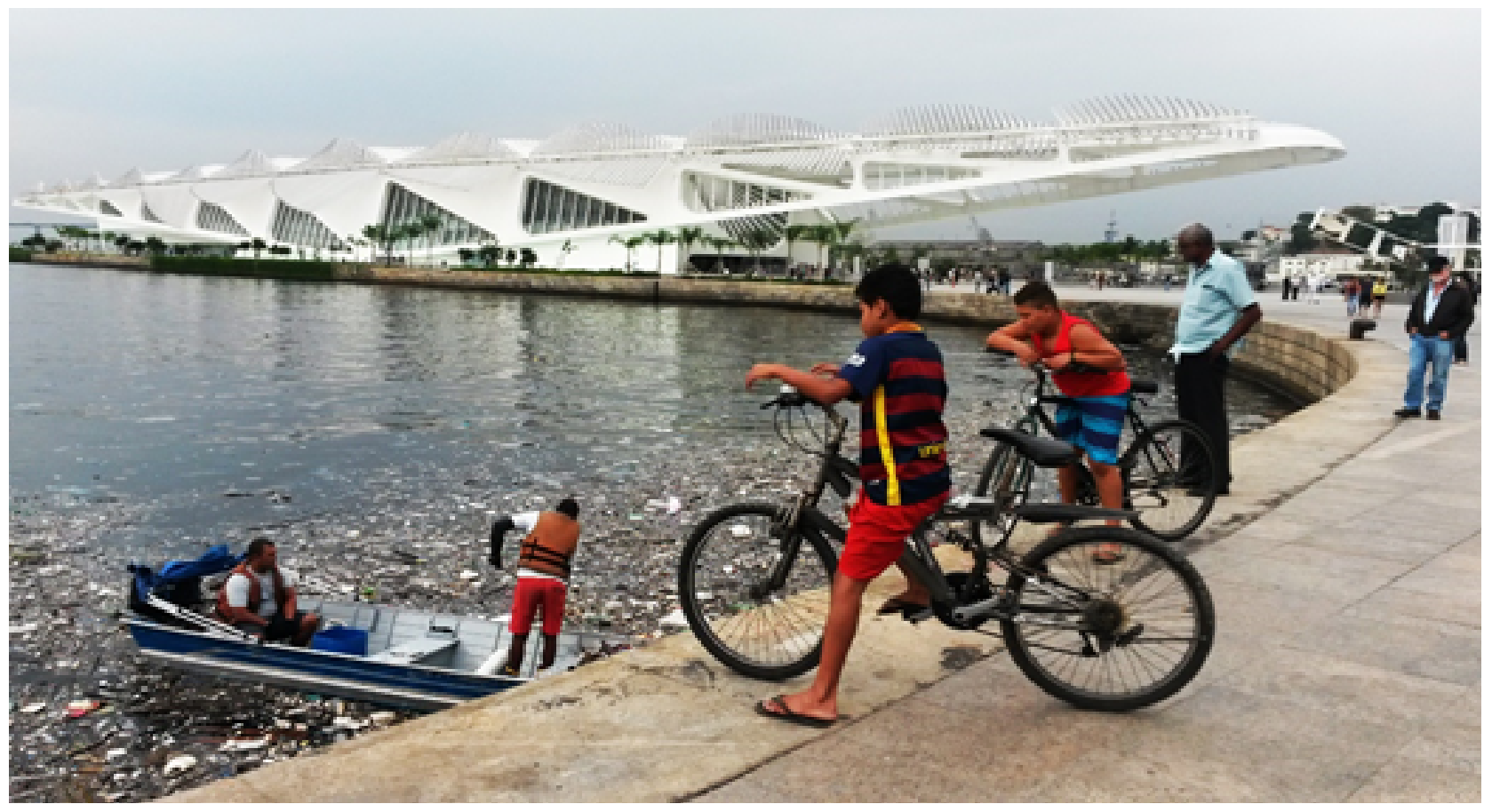

Figura 1 - Desafios para a sustentabilidade? Limpeza da Baía para retirada de lixo diário acumulado próximo ao "sustentável" Museu do Amanhã. Foto: Sayuri Dantas, 29/4/2016. 
Com relação à região Central e à Zona Portuária, além do incentivo à moradia, aos investimentos comerciais e à inovação dos usos, o IRPH busca revitalizar esses espaços para fins de turismo e de consumo cultural. Alguns desses espaços foram denominados áreas de interesse paisagístico e receberam atenção especial para serem incorporadas, como paisagem cultural, à rota turística durante a Copa do Mundo de 2014 e as Olimpíadas de 2016. Tal estratégia articulava, portanto, a política de patrimonialização à recomposição turística do Rio de Janeiro e à criação de novas imagens urbanas, com o intuito de canalizar recursos financeiros para consolidar o plano de revitalização urbana e do antigo casario edificado dessas duas áreas.

As ações mais significativas do projeto Porto Maravilha até as Olimpíadas ocorreram com a construção do Museu de Arte do Rio (2013), a revitalização da praça Mauá e a construção do Museu do Amanhã, no final de 2015, sob o slogan de inovação, criatividade e tecnologias sustentáveis. Criou-se, também, o planejamento viário de mobilidade sustentável com VLTs e ciclovias após a demolição do Elevado Perimetral. Conforme Pio (2013), o Porto Maravilha atua em quatro setores que são: a melhoria da infraestrutura (saneamento, malha viária, meio ambiente); o estímulo ao uso habitacional; o investimento comercial e industrial; e cultura e entretenimento. Apesar de o projeto almejar ações e intervenções abrangentes, "é possível notar que as atividades culturais são vistas por políticos e pela opinião pública como aspecto central e determinante do sucesso da revitalização econômica e social de espaços urbanos 'degradados"' (PIO, 2013, p. 10).

Em relação às atividades culturais, comunidades portuárias como a Pedra do Sal, no bairro Saúde, tornaram-se lugar de consumo, espaço turístico e de vida noturna carioca. A abrangência da política de patrimonialização não se restringe somente à construção de equipamentos urbanos. Promovem-se espaços do entorno como pontos de cultura, caso da região da Pedra do Sal conhecida como Pequena África, por ser considerada um território étnico de cultura afro-brasileira, tombada entre 1984 e 1987, pelo Instituto Estadual do Patrimônio Cultural (INEPAC), após o reconhecimento dos degraus escavados na pedra que dão acesso ao Morro da Conceição e dos bens imateriais como o samba de raiz e os blocos carnavalescos que fazem parte do cotidiano e imaginário carioca (OLIVEIRA et al, 2012; GUIMARÃES, 2012).

Embora a preservação patrimonial e do meio ambiente colabore com o desenvolvimento urbano e econômico da cidade, o outro lado da história, digamos, ocorre em função das políticas de valorização paisagística em torno da patrimonialização e dos próprios megaeventos, quando se intensificou a remoção de ocupações em morros favelizados e de cortiços na área central e portuária, sob o discurso da "ordem urbana", de segurança pública, combate à violência e ao tráfico de drogas que legitimou a instalação das Unidades de Polícia Pacificadora (UPPs). Conforme Diniz (2014, p. 13), “os princípios de ordem, racionalidade, normatização e funcionalidade nas políticas de renovação urbana sustentaram intervenções que, segundo seus críticos, negligenciaram os atributos históricos dos espaços urbanos e os modos de vida a eles associados".

As favelas voltaram às atenções midiáticas desde 2010, após o Rio ser eleita cidade-sede das Olimpíadas, e passaram a ser relacionadas - negativamente - aos discursos ecológicos de preservação ambiental e sustentabilidade dos morros da Zona Sul. Tal perspectiva envolve a ideia de desfavelização, como demonstram os estudos de MATTOS (2014) e STEIKERGINZBERG (2014), para combater o crescimento e reverter a política de urbanização de favelas, a exemplo do Programa Morar Carioca (2010), uma extensão do Programa Favela-Bairro, que prometia se tornar o mais abrangente programa de urbanização de favelas do Rio através de modernização, infraestrutura e integração entre as favelas da cidade até o ano de 2020. Conforme Mattos (2014, p. 173), "está em curso na cidade do Rio de Janeiro a construção da legitimação da remoção de favelas como política permanente, o que pode jogar por terra o consenso que se formou em torno da urbanização durante os últimos 30 anos". 




Figura 2 - Vila Santo Amaro - Vista do Parque das Ruínas. Santa Tereza, Rio de Janeiro, 2012. Fonte: Leandro Neumann Ciuffo. Imagem licenciada em Creative Commons Attribution 2.0 Generic (CC BY 2.0).

Desde os anos de 1970, através da prática do favela-tour, nas diversas regiões da cidade do Rio de Janeiro, diversas comunidades de baixo poder aquisitivo, como Pavão-Pavãozinho, Vidigal, Rocinha, Morro da Providência, Morro do Alemão etc., residentes em áreas consideradas com vista paisagística privilegiada, viram seus espaços cotidianos sendo apropriados pelos processos de turistificação da vida cotidiana (VAN DER DUIM, 2007), isto é, foram transformadas em destinos turísticos oficiais na agenda cultural carioca o que foi intensificado com a presença das UPPs. Esse processo envolve uma dupla condição associada à paisagem turística: por um lado, as remoções que levam à expulsão de moradores sob o argumento de irregularidades da ocupação e uso do solo; por outro, estimula os investimentos turísticos em áreas favelizadas e oculta o "texto visível" de símbolos e materialidade de poder estatal, financeiro e midiático das ações do poder público em torno das remoções, ao privilegiar certos lugares de visitação dentro das favelas para promover o turismo. Como nota Fortuna (2012, p. 33), a sensação “de se 'pertencer' e compartilhar uma comunidade e uma determinada 'experiência' coletiva. Mesmo quando essa 'experiência' se enuncia como sinal de perda cultural e afronta à democracia e à dignidade humana". Para o autor, essa condição incorre em um "incontido voyeurismo" em visitar a "pobreza turística" (Idem, ibidem.). Neste sentido, para Jaguaribe:

Dos ideários de cosmopolitismo e modernidade expressos pelas comemorações do Centenário de 1922 aos preparativos para as Olimpíadas de 2016, o Rio de Janeiro transformou-se de uma cidade periférica em uma metrópole em busca de uma nova configuração. A favela tornou-se trademark, a cultura popular e midiática suplantou os ideários da cidade letrada Belle Époque, e a espetacularização do espaço público se consagra não mais como tarefa civilizatória ou cenário do nacional, mas enquanto oferta cultural e formas de consumo globais. (Ibid., p. 345).

Essa relação entre patrimônio, sustentabilidade e desenvolvimento econômico tem sido associada às políticas urbanas voltadas às práticas de revitalização dos centros históricos e áreas portuárias, mas com o conceito de paisagem cultural não se perdem devista as áreas de interesse para a valorização paisagística. Podemos afirmar que essa mediação da economia de mercado 
vincula os processos de mudança das identidades urbanas às inovações dos bens culturais em oferta. Tanto podem ser comunidades étnicas, centros históricos ou simplesmente as paisagens culturais em que suas incidências identitárias são recursos para o branding publicitário (JAGUARIBE, 2011), na construção dos lugares turísticos onde a vida cotidiana e as retóricas atribuídas aos bens patrimoniais parecem fundirse, ocorrendo constante reprodução, modificação e apropriação para novos usos. Dessa forma, a orientação pelas práticas de mercado revela-se na "generalização" de casos de enobrecimento, através da espetacularização das paisagens, dos espaços e da cultura (LEITE, 2010, 2015) tanto dos espaços patrimoniais, quanto das localidades mais desfavorecidas, nesse caso, as comunidades favelizadas em morros paisagísticos.

\section{Considerações finais}

Dada a ênfase das políticas urbanas de patrimonialização na agregação de valor da paisagem cultural para o desenvolvimento econômico, social e do ambiente cultural das cidades, podemos perceber como tal conceito é articulado ao turismo e à imagem urbana "consumível". A paisagem torna-se expressão da reprodução do mundo material e imaterial, dos sentidos históricos, culturais e representativos das cidades e sítios históricos. Aponta também, de modo às vezes implícito, para o impacto das mudanças contemporâneas das práticas sociais e no modo como os agentes, pessoas e instituições - os grupos de interesse -, definem os espaços urbanos consumíveis.

A nova política urbana em torno da paisagem cultural carioca tanto visa uma política de proteção e sustentabilidade socioambiental dos morros e espaços litorâneos, quanto de deslocamento dos fluxos de investimentos públicos e privados diversos para as áreas central e portuária. $\mathrm{O}$ reordenamento da cidade decorre da política de valorização paisagística, de revitalização urbana e de criação de novas e opulentas paisagens turísticas em tais áreas.

A realização de parcerias entre a PCRJ e os setores privados nacionais e internacionais almejou altos investimentos financeiros para consolidar as políticas sustentáveis, sendo esses investimentos, apesar das definições das APACs, promotores de forte especulação na expansão, renovação ou revitalização imobiliária das áreas consideradas paisagísticas. Para os administradores da cidade, sediar as Olimpíadas, por exemplo, tornou-se a oportunidade de demarcar, na trajetória do urbanismo carioca, um legado próprio de transformações urbanas, ao passo que confirmaria o valor patrimonial da paisagem cultural como o resultado das ações e das práticas sociais de desenvolvimento urbano.

Estas transformações consubstanciam as intervenções urbanas à turistificação da vida cotidiana, confirmando as práticas mercadológicas contemporâneas em torno da reinvenção das imagens urbanas - e mesmo da própria cidade, promovida pelos setores empresariais, publicitários, de eventos, redes sociais etc. Essas características enunciam a plural, porém conflitiva, relação entre a recomposição imagética e paisagística da cidade do Rio de Janeiro e sua orientação pelo valor de consumo da paisagem - o que torna a política de proteção paisagística um recurso metonímico da patrimonialização. No entremeio desse conflito, continua, ainda, o propósito de vencer as favelas - seja pela exclusão seletiva de alguns destes espaços do mapa turístico e cultural carioca, seja através da valorização da contra-paisagem numa paisagem turística.

\section{Referências}

BARBOSA, Jorge Luiz. "Paisagens da Natureza, Lugares da Sociedade: a construção imaginária do Rio de Janeiro como 'cidade maravilhosa"' In: SILVA, Jailson S.; BARBOSA, J. L.; FAUSTINI, M. V. (orgs.). O novo carioca. Rio de Janeiro: Mórula Editorial, 2012, p. 23-42.

BROUDEHOUX, Anne-Marie; MONTEIRO, João Carlos C. dos S.. "Reinventing Rio de Janeiro's old port: territorial stigmatization, symbolic resignification, and planned repopulation in Porto Maravilha". In: Revista Brasileira de Estudos Urbanos e Regionais, vol. 19, $\mathrm{n}^{\circ} 3$, p. 493-512, 2017.

CARLOS, Claudio Antonio S. L.. Áreas de proteção do ambiente cultural (Apac): Da idealização à 
banalização do patrimônio Cultural carioca. Tese (Doutorado em Urbanismo) - da Faculdade de Arquitetura e Urbanismo UFRJ, Rio de Janeiro, 2008.

COSTA, Luciana de Castro N.; SERRES Juliane Conceição P.. "Paisagem Cultural: discussões contemporâneas por um (novo) olhar para o patrimônio cultural". In: Ciências Sociais Unisinos. vol. 52, no 1, p. 35-44. 2016.

DINIZ, Nelson. Porto Maravilha: antecedentes e perspectivas da revitalização da região portuária do Rio de Janeiro. Rio de Janeiro, Letra Capital, 2014.

FARIAS, Edson. "'Cidade Maravilhosa', 'Rio Babilônia' e 'Rio 40 Graus': três signos na economia simbólica da paisagem carioca". In: Revista de Ciências Sociais, vol.48, n 1 , p.155207, 2017.

FEATHERSTONE, Mike. Consumer Culture and Postmodernism. 2nd ed., London: Sage, 2007.

. "Societal value formation and the value of life". In: Current Sociology. vol. 59, no 2, p. 119134, 2011.

FORTUNA, Carlos. "Destradicionalização e imagem da cidade: o caso de Évora". In: FORTUNA, C. (org.) Cidade, cultura e globalização: ensaios de sociologia. Oeiras, Celta, 1997, p. 231-258.

Património, turismo e emoção. In: Revista Crítica de Ciências Sociais. Coimbra, vol. 97, p. 23-40, 2012.

GUIMARÃES, Roberta Sampaio. "De monumento negro a território étnico: os usos do patrimônio cultural na produção de espaços urbanos diferenciados". In: TAMASO, Izabela Maria; FILHO, Manuel Ferreira L. (orgs). Antropologia e Patrimônio Cultural: trajetórias $e$ conceitos. Brasília, Associação Brasileira de Antropologia, 2012, p. 299-318.

"O patrimônio cultural na gestão dos espaços do Rio de Janeiro”. In: Estudos Históricos.
Rio de Janeiro, vol. 29, n 57, p. 149-168, 2016.

HOLBROOK, Morris. B. et al. Consumer value: a framework for analysis and research. Routledge: London, 1999.

IPHAN. Rio de Janeiro: paisagens cariocas entre a montanha e o mar. Dossiê de Candidatura do Rio de Janeiro à Lista de Patrimônio da Humanidade. Brasília, Iphan, 2012.

JAGUARIBE, Beatriz. "Imaginando a 'cidade maravilhosa': modernidade, espetáculo e espaços urbanos". In: Revista Famecos, vol. 18, no 2, p. 327-347, 2011.

LEITE, Rogerio Proença. “A exaustão das cidades: antienobrecimento e intervenções urbanas em cidades brasileiras e portuguesas". In: Revista Brasileira de Ciências Sociais. São Paulo, vol. 25, no. 72, pp. 73-175, 2010.

"Cities and Gentrification in Contemporary Brazil”. In: Current Urban Studies. vol. 3, no 3, p. 175-186, 2015.

MALTA, Eder. "Consumindo paisagens: patrimônio cultural, turismo e enobrecimento urbano no Rio de Janeiro". In: TOMO, n 31 , pp. 91-134, 2017a.

"Patrimonialização, sustentabilidade e consumo: a recomposição da paisagem cultural do Rio de Janeiro". In: Revista de Ciências Sociais Unisinos, vol. 53, n 3, 2017b.

MATTOS, Romulo Costa. "Remoções de favelas na cidade do Rio de Janeiro: uma história do tempo presente". In: Outubro, no 21, p. 171-190, 2014

OLIVEIRA, Carmen Irene C. et al. "Pedra do Sal e samba na fonte: samba de raiz em um espaço fundador na perspectiva das paisagens culturais". In: TAMASO, M. I. e FILHO, M. F. L. (orgs.). Antropologia e patrimônio cultural: trajetórias $e$ conceitos. Brasília, Associação Brasileira de Antropologia, 2012, p. 265-298.

PIO, Leopoldo Guilherme. "Cultura, patrimônio 
e museu no Porto Maravilha". In: Revista Intratextos. Rio de Janeiro, vol. 4, no 1, p. 8-26, 2013.

PREFEITURA DA CIDADE DO RIO DE JANEIRO. Plano Diretor de Desenvolvimento Urbano Sustentável do Município do Rio de Janeiro. Lei Complementar n. 111/2011. Rio de Janeiro, PCRJ, 2011.

. Decreto n. 35.879 de 5 de julho de 2012.

RIBEIRO, Rafael Winter. "Possibilidades e limites da categoria de paisagem cultural para formação de políticas de patrimônio". In: CUREAU, S.; et al. (orgs.). Olhar multidisciplinar sobre a efetividade de proteção do patrimônio cultural. Belo Horizonte: Fórum, 2011, p. 254-267.

SAUERBRONN, João F. R.; AYROSA, Eduardo A. T.. "Valores de Consumo: explorando a prática e o consumo de esportes". In: Revista Interdisciplinar de Marketing, vol 3, n 1, p. 5-21, 2004.

SCHRÖDER, Monika J.A.; MCEACHERN, Morven G.. "Fast foods and ethical consumer value: a focus on McDonald's and KFC". In: British Food Journal. vol. 107, no 4, p. 212-224, 2005.

STEIKER-GINZBERG, Kate. "Morar carioca: o desmantelamento do sonhado programa de urbanização para as favelas". In: Rio on Watch, 25 set. 2014. Disponível em: <http://rioonwatch. org.br/?p=12410>. Acesso em: nov. 2017.

UNESCO. Committee Decisions ( $36^{a}$ Convention): Cultural Properties - Rio de Janeiro, Carioca Landscapes between the Mountain and the Sea (Brazil), WHC.12/36.COM /19, 2012. Disponível em: <http://whc.unesco.org/en/decisions/4813>. Acesso em: out. 2017.

VAN DER DUIM, René. “Tourismscapes. An Actor-Network Perspective". In: Annals of Tourism Research, vol. 34, no 4, p. 961-976, 2007.

ZUKIN, Sharon. "Paisagens urbanas pósmodernas: mapeando cultura e poder". In:
ARANTES, A. (org). O espaço da diferença. Campinas: Papirus, 2000, p 80-103.

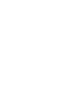

